\title{
The Impact of Pre-task Instruction and Task Rehearsal on Fluency, Accuracy and Complexity of Iranian EFL Learners' Writing
}

\author{
Ghorbanali Salehi Aref \\ English Department, Faculty of Literature and Humanities, Islamic Azad University, Science and Research Branch of \\ Tehran, Tehran, Iran \\ Ahmad Mojavezi \\ English Department, Faculty of Literature and Humanities, Islamic Azad University, Science and Research Branch of \\ Najafabad, Isfahan, Iran
}

\begin{abstract}
The purpose of this study was to examine the impact of pre-task instruction and task rehearsal, on fluency, accuracy, and complexity of Iranian EFL learners' writing. To achieve this, Forty-five foreign language learners with little access to the 12 outside the classroom participated in this study. They were both male $(44 \%)$ and female $(56 \%)$. Measures of fluency, accuracy, and complexity were utilized to measure students' writing. Data were analyzed using MANOVA and ANOVA. The results of the study revealed that pre-task instruction and task rehearsal have positive effect on the learners' writing. The result of the study and their pedagogical implications were discussed.
\end{abstract}

Index Terms — pre-task instruction, task rehearsal, second language writing, accuracy, fluency, complexity

\section{INTRODUCTION}

Second language acquisition researchers have studied the notion of planning with reference to different theories; One of these models is the "computational model"(Lantolf, 1996), which is based on an analogy between the human mind and a computer by which human being possesses limited capacity in terms of the amount of information that can process from input to output. These limits can lead language learners to prioritize one aspect of language over another. Levelt's (1989) model of speech production, on the other hand, considers speakers as complex information processors who are capable of translating intention, thought, and feeling into articulated speech. Three categories of autonomous processing in language production are established by this model: (a) message conceptualization, (b) formulation of language representation, and (c) message articulation.

In the course of the most recent 20 years, the lion's share of concentrates on task planning have been focused on L2 students' oral discourse (Bygate, 2001; Ellis, 2003; Mojavezi, 2014). We have taken in a lot about how the chance to design previously or amid an assignment may enhance a few parts of L2 discourse. However, we have little knowledge about what L2 learners actually do to plan for a task. In the meantime, there is currently a hot debate between Skehan's trade-off hypothesis $(1998)$ and Robinson's $(2001,2007)$ cognition hypothesis and all of the studies which have tested these two hypotheses and have tried to falsify one of them have focused on oral performance. This study tries to shed light on the effect of pre-task instruction and task rehearsal on writing ability. In other words, an important goal of this study would be to see which hypothesis (cognition or trade-off) is more consistent with the data which will be obtained in an EFL context.

\section{REVIEW OF LITERATURE}

Recent years have seen enormous growth of interest in task-based language learning and teaching. There are several reasons for this surge of interest. First, a 'task' is a construct of equal import to both second language acquisition researchers and language teachers (Ellis, 2003). Second, task-based pedagogy is capable of a wide range of interpretations. That is, any single task, Ellis (2003) states, has the potential to be performed in a number of ways, depending on how the participants orient to it. This perceived flexibility of task-based tradition can deflect some of the criticisms leveled against it. One of these criticisms is based on the claim that performing tasks and language use does not necessarily lead to fluent and accurate production or language acquisition (Reinders, 2009).

From the vantage point of information processing theories, this is in part due to the fact that language learners' attentive or processing capacity is restricted, and hence, they cannot process 'schematic' and 'systemic' knowledge simultaneously (see Carroll, 2008; Ellis, 1994, 2003, 2005; Skehan, 1998a, 1998b, 2007a; Skehan \& Foster 1999, 2001; Van Patten, 2009). This being so, language learners tend to bypass language form in favor of meaning drawing on their wide repertoire of communicative strategies to which they have access (Skehan, 1998a). 


\section{A. Concept Mapping; a Form of Pre-task Instruction}

In this study, concept mapping (conceptual diagram) is considered as an instructional strategy and its capabilities for ameliorating written production of ESL (English as a Second Language) learners are investigated. Hanf (1971) was the first who created Concept mapping as a model so as to enhance the educating of study aptitudes. It typically begins with who produce words identified with the subject and order them into gatherings of related words. At that point, understudies build up their contemplation about the subject and draw authoritative structures, which can either be direct or various leveled. There are various terms under which the technique of concept mapping has been practiced and investigate including semantic mapping (e.g., Cronin, et al., 1992; Heimlich and Pittelman, 1986; Lipson, 1995; Schultz, 1991), cognitive mapping (e.g., Boyle, 1996; Peresich, et al., 1990; Reynolds and Hart, 1990) and webbing (e.g., Brown and Salisch, 1996; Norton, 1993; Pieronek, 1994). The refinement between these terms isn't clear in the writing, and they are probably going to be utilized as equal in both L1 and L2 ponders. The selection of this strategy as a target instruction is due the fact that concept mapping effective for both conceptual and linguistic development (Heimlich and Pittelman, 1986). Besides, it is widely implemented in classroom instruction.

Positive effects of concept mapping in a variety of instructional settings have been reported in some studies. For instance, it has been used as a technique to improve vocabulary (Harley et al., 1996; Johnson and Steele, 1996; Morin and Goebel, 2001), amend reading comprehension (Baumann and Bergeron, 1993; Carrell et al., 1989; Lipson, 1995; Tang, 1992), and writing skills (Cronin et al., 1992; Schultz, 1991), and assist the comprehension of concepts in subject areas (Park, et al., 1999; Roth, 1994). Concept mapping also helps students in special education programs to promote their literacy knowledge (Boyle, 1996; Englert and Mariage, 1991; MacArthur, 1996; Sinatra, et al., 1994). It is believed that concept mapping facilitate writing process (Pieronek, 1994; Renner, 1992; Rey, 2000; Washington, 1988); needless to say there are limited research on mapping and the vast majority of them were performed in L1 writing contexts. For instance, Cronin et al. (1992) contemplated a region plan process for optional schools in Mississippi, and showed that mapping techniques had supported understudies' comprehension of content association and composing forms dependent on the composition tests results over a time of four-years.

\section{B. Task Rehearsal}

To build up Task redundancy requires dialect students to be requested to rehash the equivalent or somewhat adjusted task (Bygate and Samuda 2005: 43). The main execution of the task assignment redundancy is considered as an arrangement for, or a pre-errand movement previously, more exhibitions (Ellis 2005). This may appear behaviorist drills which depend on the assumption that dialect learning happens through a propensity arrangement process by means of redundancy

In its new conceptualization nonetheless, task repetition doesn't allude to 'verbatim' redundancies of the prompts in the second language classroom; rather, it includes content and the reiteration of commonplace shape (Bygate 2006). This new conceptualization is to some extent educated by the view that our consideration and handling limit amid correspondence exercises is intrinsically confined in some imperative routes - for example, L2 students can't, center around both importance and shape all the while. By rehashing the equivalent or comparable undertakings, in this manner, students may be capable upon what they have officially done as such as to 'purchase time' not exclusively to do mental work on what they are going to impart yet in addition to get to and (re)formulate words and linguistic structures all the more productively, viably and precisely.

Comparative examples concerning impacts of task reiteration with L2 students of Spanish was seen by Gass et al. (1999), while Lynch and McLean's (2000) think about exhibited that recycling affected both fluency and accuracy in an English for Specific Purposes context. Similarly, Ahmadian and Tavakoli (2011) discover that task repetition could be employed as a pedagogic tool to direct L2 learners' effect of task repetition on complexity and fluency of L2 speech and, more recently, Hawkes' attention towards form. Generally speaking, however, research findings and empirical evidence lend support to the effectiveness of task repetition to improve language performance with some trade-off effects being reported. In reviewing task repetition literature there are three important points which need to be brought to attention: (a) design of the study (between-groups vs. repeated-measures designs); (b) the time interval between the two occasions of task performance; and (c) operationalization of 'task repetition' (whether the same task has been used or slightly altered tasks and the number of repetitions that they adopt). In the present study which is a between-groups design, there is a one-week interval between the two occasions of performing the same task. Having in mind the above mentioned points we review some closely relevant studies below. This will pave the ground for us to formulate appropriate hypotheses regarding the effects of task repetition.

\section{METHOD}

\section{A. Participants}

This study was a between-groups design that aimed to examine the effects of pre-task instruction and task rehearsal on fluency accuracy, and complexity, and fluency of EFL learners' writing.

The participants in this study were 45 intermediate level EFL learners recruited from two teacher education centers in Iran. A special effort was made to identify students who are at the same level of ability. To this aim, 160 participants 
mastering in Language Teaching and was administered "Oxford Placement Test 2" (Allan, 1992), as a pre-test, to select the students with equivalent language proficiency at the outset of the study.

\section{B. Instruments}

In this study, measures of fluency, accuracy, and complexity was used to evaluate the quality of the participants' written production:

1. Fluency measures

Estimating fluency as a build in composing has been a hot discussion from the 1970s. In the main endeavor, Hunt (1970) attempted to gauge learners' L1 composing familiarity. He connected the develop of a T-unit, or insignificant terminal unit, which joined by any related ward provisions. He chose T-units rather than sentence length, since it was perceived that kids in their local dialect could and would compose long sentences just by utilizing coordination. More recent studies validated this construct by using the number of syllables per minute (e.g., Chenoweth, A., \& Hayes (1998), Chenoweth and Hayes (2001), Ellis and Yuan (2004), Ellis and Yuan (2005).

According the theoretical principium for measuring fluency, this study will employ the same measures utilized by Chenoweth and Hayes \& Ellis and Yuan (2004) for measuring writing fluency, i.e. syllable per- minute: the total number of syllables produced divided by the total number of seconds a contributor will take to complete the task multiplied by 60 .

2. Complexity measures

a. Syntactic complexity: it is regarded as the ratio of clauses to T-units in the contributors' production. in this study, $\mathrm{T}$-unit will be employed instead of $\mathrm{C}$-unit since the task performance is mono-logic and contains few elided utterances. It should be mentioned that $\mathrm{T}$-unit analysis was primarily developed to evaluate written language and has been replaced by C-unit analysis for oral production.

b. Syntactic variety: The aggregate number of various linguistic action word frames utilized in the undertaking is called Syntactic assortment Grammatical action word shapes comprise tense (e.g., straightforward past, past persistent), methodology (e.g., should, need to), and aloof voice.

3. Accuracy measures

For accuracy measurement the following two criteria will be used:

a) Error-free clauses: the percentage of clauses that do not contain any errors. Errors were defined as deviant from standard norms with respect to syntax, morphology, and/or lexicon. Lexical errors are defined as errors in lexical form or collocation (e.g., *I was waiting you). So, all errors in syntax, morphology, and lexical choice will be considered.

b) Correct verb forms:

The level of accuracy utilized action words regarding tense, viewpoint, methodology, and subject-verb agreement.3.4. Procedures

3.4.1. Data collection

For data collection, the participants were required to write an argumentative under the different planning conditions. The topic was: "Some people believe that watching Television is harmful. Others maintain that it is beneficial. What is your idea? Use specific reasons and examples to support your idea".

3.4.2. Data Analysis

We segmented, coded, and scored all writing productions of different groups under the aforesaid conditions based on the measures selected for assessing complexity, accuracy, and fluency. The data was segmented, coded, and scored by two independent experts in order to ensure that the segmentation and scoring of the transcripts are conducted reliably. In the next step, inter-coder/inter-rater reliability coefficient magnitudes was estimated. SPSS version 22.0 was employed to check the normality of distribution via skewness and kurtosis indices. Each aspect of accuracy and complexity was submitted to MANOVA. Finally writing fluency was measured using one- way ANOVA followed by Post-Hoc Tukey tests.

\section{RESULTS AND DISCUSSION}

In the present study the impacts of pre-task instruction and task rehearsal on accuracy, complexity, and fluency of EFL learners' writing were investigated. This study tried to examine the following research hypothesis:

The first research hypothesis was directed toward identifying the impact of pre-task instruction and task rehearsal on complexity writing of Iranian EFL learners. It was hypothesized that pre-task instruction and task rehearsal have no influence on EFL Learners' writing complexity. To this aim, complexity was measured in two different ways: syntactic complexity and syntactic variety. So, the higher the obtained score, the better the complexity of language would be. Table4.1. summarizes the descriptive on learners' complexity writing. 
TABLE 4.1.

DESCRIPTIVE STATISTICS ON STUDENTS' WRITING COMPLEXITY

\begin{tabular}{|l|l|l|l|l|l|l|}
\hline Groups & $\mathrm{N}$ & Minimum & Maximum & Mean & Std. Deviation & Variance \\
\hline S. complexity (Group 1) & 15 & 1.10 & 1.60 & 1.28 & .14 \\
S.Complexity(Group 2) & 15 & 1.30 & 1.70 & 1.49 & .11 \\
S. complexity (Group 3) & 15 & 1.50 & 2.30 & 1.86 & .22 & .021 \\
S. variety (Group 1) & 15 & 11.10 & 16.50 & 13.54 & 1.59 & .014 \\
S. variety (Group 2) & 15 & 14.40 & 22.30 & 17.51 & 2.70 & .051 \\
S. variety (Group 3) & 15 & 15.60 & 32.10 & 22.33 & 2.78 & \\
Valid N (list wise) & 15 & & & & & \\
\hline
\end{tabular}

As indicated in table 4.1.it became clear that mean scores on syntactic complexity and syntactic variety of group three is more than groups two and one. Group three preformed significantly differently from both groups two and one. Also learners in group two outperformed those in group one. Thus it can be inferred that the mean scores of learner group two is higher than that of group one. However, In order to test the null hypothesis, a one-way between -group multivariate analysis of variance (MANOVA) was performed to explore the effect of pre-task guidance and task practice on syntactic multifaceted nature and syntactic assortment of EFL students. To check for ordinariness, linearity, univariate and multivariate exceptions, homogeneity of difference covariance lattices, and multicollinearity, Preliminary supposition testing was performed.

Checking preliminary assumption on using MANOVA, the researcher conducted Multi-Analysis of Variance (MANOVA). The result of this analysis is shown in table 4.4.

TABLE 4.4.

TESTS OF BETWEEN-SUBJECTS EFFECTS

\begin{tabular}{|ll|l|l|l|l|l|}
\hline Source & Dependent Variable & Type III Sum of Squares & D.F & Mean Square & F & Sig. \\
\hline \multirow{2}{*}{ Groups } & Syntactic -complexity & 2.59 & 2 & 1.29 & 45.36 \\
& Syntactic-variety & 523.75 & 2 & 261.87 & .000 \\
\hline
\end{tabular}

Table 4.4 shows syntactic complexity and syntactic variety are significant $(\mathrm{p}=.000)$. F value was significant. This suggests that there is significant difference between / among the groups. It is also necessary to find out where the difference is stated. Hence, The Null Hypothesis has been rejected. To further examine the place of differences between the groups, Post-Hoc Tukey test was conducted. The result of the Post-Hoc indicated in table 4.5.

TABLE4.5.

POST-HOC TUKEY TEST

\begin{tabular}{|c|c|c|c|c|c|}
\hline Dependent Variable & (I) Groups & (J) Groups & $\begin{array}{l}\text { Mean } \\
\text { Difference }(\mathrm{I}-\mathrm{J})\end{array}$ & Std. Error & Sig. \\
\hline \multirow{6}{*}{ Syntactic complexity } & \multirow[t]{2}{*}{ no planning } & $\begin{array}{l}\text { Pre-task instruction without task } \\
\text { rehearsal }\end{array}$ & $-.20^{*}$ & .061 & .005 \\
\hline & & task planning with task rehearsal & $-.58^{*}$ & .061 & .000 \\
\hline & \multicolumn{2}{|c|}{ Pre-task instruction without no planning } & $20^{*}$ & .061 & .005 \\
\hline & task rehearsal & task planning with task rehearsal & $-.37^{*}$ & .061 & .000 \\
\hline & \multirow{2}{*}{$\begin{array}{l}\text { task planning with task } \\
\text { rehearsal }\end{array}$} & no planning & $.58^{*}$ & .061 & .000 \\
\hline & & $\begin{array}{l}\text { Pre-task instruction without task } \\
\text { rehearsal }\end{array}$ & $37^{*}$ & .061 & .000 \\
\hline \multirow{6}{*}{ Syntactic variety } & \multirow[t]{2}{*}{ no planning } & $\begin{array}{l}\text { Pre-task instruction without task } \\
\text { rehearsal }\end{array}$ & $-3.97^{*}$ & 1.26 & .008 \\
\hline & & task planning with task rehearsal & $-8.35^{*}$ & 1.26 & .000 \\
\hline & \multicolumn{2}{|c|}{ Pre-task instruction without no planning } & $3.97^{*}$ & 1.26 & .008 \\
\hline & task rehearsal & task planning with task rehearsal & $-4.38^{*}$ & 1.26 & .003 \\
\hline & \multirow{2}{*}{$\begin{array}{l}\text { task planning with task } \\
\text { rehearsal }\end{array}$} & no planning & $8.35^{*}$ & 1.26 & .000 \\
\hline & & $\begin{array}{l}\text { Pre-task instruction without task } \\
\text { rehearsal }\end{array}$ & $4.38^{*}$ & 1.26 & .003 \\
\hline
\end{tabular}

The above table indicates syntactic complexity and syntactic variety in the three groups.

Thinking about syntactic unpredictability, the exposition by organizers who had both pre-errand guidance and undertaking practice contained the most linguistically complex sentences, averaging 1.86 conditions per T-unit, though the individuals who had no pre-assignment arranging Without any chance to practice the assignment furnished the slightest grammatically complex with 1.28 provisions per T-unit.

Regarding syntactic varieties, as measured by the total number of different grammatical verb forms used in the task, the essay by planners who had both pre-task planning and task rehearsal contained the most syntactically complex sentences, averaging 22.33 clauses per T-unit, whereas those who had no pre-task planning Without any opportunity to rehearse the task provided the least syntactically complex with 13.54 clauses per T-unit.

The results of this study support the findings of the previous studies suggesting significant differences among the groups with different task conditions. Task complexity in Robinson's theory is defined by two sets of aspects, 'resource 
directing' (e.g. whether the task needs reasoning) and 'resource depleting' (e.g. whether there is opportunity for strategic planning). These two factors 'interact and affect task production in measurable ways' (p. 31). On the contrary, accuracy and specially complexity are achieved by learners drawing on their rule-based system and therefore require syntactic processing. Complexity is different from accuracy since it is related to the 'restructuring' that arises as a result of the need to take risks whereas accuracy reflects the learner's attempt to control existing resources and to avoid errors.

Additionally, the aftereffects of this investigation, bolster Ellis (2003, 2008) Ellis and Barkhuizen (2005) thoughts, who trust that intricacy is resolved as the degree to which the dialect delivered in playing out an errand is intricate and shifted (Ellis 2003, p.340) and identified with students' propensity to go for broke to utilize the most exceptional of their semantic which may finally give rise to the process of restructuring (Ellis, 2008; Ellis \& Barkhuizen, 2005). Thus, these findings led to the rejection of the first Null Hypothesis.

The second research hypothesis was directed toward identifying the impact of pre-task instruction and task rehearsal on accuracy writing of Iranian EFL learners. It was hypothesized that pre-task instruction and task rehearsal have no influence on EFL Learners' writing accuracy. Accuracy was measured in two ways: Error-free clauses and Correct-verb forms. In order to test the null hypothesis, a one-way between -group multivariate analysis of variance (MANOVA) was performed to investigate the impact of pre-task instruction and task rehearsal on syntactic complexity and syntactic variety of EFL learners. Initial assumption testing was conducted to check for normality, linearity, univariate and multivariate outliers, homogeneity of variance-covariance matrices, and multicollinearity. The results of the analysis suggested no violation on the assumptions. Table 4.6. shows the related descriptive statistics on students' writing accuracy.

TABLE 4.6.

DESCRIPTIVE STATISTICS ON STUDENTS’ WRITING ACCURACY

\begin{tabular}{|l|l|l|l|l|l|}
\hline & $\mathrm{N}$ & Minimum & Maximum & Mean & Std. Deviation \\
\hline Correct_verb_G1 & 15 & .69 & 1.30 & 1.00 & .20 \\
Correct_verb_G2 & 15 & .68 & 79.00 & 6.19 & 20.14 \\
Correct_verb_G3 & 15 & .87 & 1.50 & 1.20 & .20 \\
Error_free_G1 & 15 & .06 & 1.10 & .71 & .23 \\
Error_free_G2 & 15 & .59 & 1.30 & .87 & .18 \\
Error_free_G3 & 15 & .78 & 1.40 & 1.00 & .16 \\
Valid N (list-wise) & 15 & & & & \\
\hline
\end{tabular}

As mentioned, the above table indicates descriptive statistics on students' writing accuracy. Group one are the students with no pre-task instruction and task rehearsal, group two are the participants with pre-task instruction without task rehearsal, and group three are the students having opportunities for both pre-task instruction and task rehearsal.

The consequence of the analysis demonstrates that group three had the most astounding mean on the two measures, trailed by gathering two, and gathering one had the least mean. Nonetheless, In request to test the second invalid theory, a one way ANOVA analysis between - aggregate multivariate examination of difference (MANOVA) was performed to explore the effect of pre-task instruction and task rehearsal.

TABLE 4.7 .

POST-HOC ON STUDENTS' ACCURACY

\begin{tabular}{|ll|l|l|l|l|}
\hline Source & Dependent Variable & d. f. & Mean Square & F & Sig. \\
\hline \multirow{2}{*}{ Corrected Model } & Correct-verb-forms & 2 & .02 & .95 & .39 \\
& Error-free-clauses & 2 & .16 & 4.87 & .01 \\
Intercept & Correct-verb-forms & 1 & 46.65 & 1514.27 & .000 \\
& Error-free-clauses & 1 & 31.43 & 955.91 & .000 \\
Groups & Correct-verb-forms & 2 & .02 & .95 & .39 \\
& Error-free-clauses & 2 & .16 & 4.87 & .01 \\
\hline
\end{tabular}

As the above table indicates the significant level for correct verb form is . 39 and error -free clauses is .01. So we can infer that the result of analysis is not significant. So the null hypothesis has been retained.

The third research hypothesis was directed toward identifying the impact of pre-task instruction and task rehearsal on fluency writing of EFL learners. It was hypothesized that pre-task instruction and task rehearsal have no influence on EFL learners' writing fluency. To this end, fluency was measured in One-way ANOVA. The researcher used the Construct of a T-units or minimal unit rather than sentence length T-units. So, the higher the obtained score, the better the fluency of language would be.

TABLE4.8.

ONE-WAY ANOVA FOR FLUENCY

\begin{tabular}{|l|l|l|l|l|l|}
\hline & Sum of Squares & D. f. & Mean Square & F & Sig. \\
\hline Between Groups & 7.71 & 2 & 3.85 & 62.36 & .000 \\
Within Groups & 2.59 & 42 & .06 & & \\
Total & 10.31 & 44 & & & \\
\hline
\end{tabular}


As indicated in the above table, the result of between groups one-way ANOVA is significant. However, in order to show the difference between the groups Tukey Post- hoc tests were conducted. The result of the Post-Hoc is indicated in table (4.9.).

TABLE4.9

MultiPle COMPARISONS

Dependent Variable: Fluency

\begin{tabular}{|c|c|c|c|c|}
\hline (I) Groups & (J) Groups & Mean Difference (I-J) & Std. Error & Sig. \\
\hline \multirow[t]{2}{*}{ no planning } & $\begin{array}{l}\text { Pre-task instruction without task } \\
\text { rehearsal }\end{array}$ & $-.24^{*}$ & .09 & \\
\hline & task planning with task rehearsal & $-.97^{*}$ & .09 & .000 \\
\hline \multirow{3}{*}{ Pre-task instruction without task rehearsal } & no planning & $24^{*}$ & .09 & .03 \\
\hline & task planning with task rehearsal & $-.73^{*}$ & .09 & .000 \\
\hline & no planning & $.97^{*}$ & .09 & .000 \\
\hline task planning with task rehearsal & $\begin{array}{l}\text { Pre-task instruction without task } \\
\text { rehearsal }\end{array}$ & $.73^{*}$ & .09 & .000 \\
\hline
\end{tabular}

As needs be, these outcomes lead to dismiss the third Null Hypothesis too. With respect to familiarity with thinking of, it tends to be guessed that pre-task guidance help familiarity with writing in two noteworthy ways: First, it simplifies process and text planning for content and organization. This affects the pre-task instructors obtain the related information that needs to be conveyed, establishes the context and explains the characters, identifies the main events, and evaluates them will find the pressure on working memory lessened during on-line assembly (Raab, 1992, cited by Zimmerman, 2000) Second, pre-task instruction may aid to boost second language writers' confidence in their capacity to write effectively and sufficiently. Therefore, may reduce their need to engage in extensive monitoring, Zimmerman suggested that writers do revise more when writing in their L2 than in their L1.It was find by Chenoweth and Hayes (2001) that second language writers who were more skillful wrote more fluently than less skilled writers; pre-task planning, hence, may compensate for lack of L2 proficiency where fluency is dealt with. The results of this study confirmed the findings of the previous related studies and this shows that there are significant differences among the groups having different task conditions.

The result of this study, also, support Foster \& Skehan (1996) ideas, believe that a number of studies have shown that when learners have the opportunity to plan a task Task repetition is perceived to be particularly helpful to advance students' familiarity and multifaceted nature. Maybe the reason is that "when students realize what they will speak or expound on they have all the more handling space accessible for planning the dialect expected to express their thoughts with the outcome that the amount of the yield will be improved and furthermore the familiarity and intricacy. (Ellis, 2003).

An alternative view, promulgated by Robinson, is that pre-task planning simplifies the task and thus obviates the need to attend closely to form during performance but assists automatic access to stored language and so leads to greater fluency.

\section{CONCLUSION}

The key finding of this research, as discussed in the preceding chapters was as follow: First, the analyses indicated that there is reasonably positive correlation between pre-task instruction, task rehearsal and some aspects of learners' writing. This study revealed that learners with having opportunity, pre-task instruction and task rehearsal try to improve their writing. Secondly, the study showed that there is a significant positive correlation between task rehearsal, pre-task instruction and EFL learners' writing achievement. In other word, having higher opportunity in pre-task instruction and task rehearsal, the higher the learners' achievement in writing. In summary, it is obvious that pre-task instruction raises output in a written task. This is revealed in higher degree, fluency, and complexity of language, although such planning seems to have little effect on accuracy.

\section{Implications of the study}

Teachers and researchers are well-aware of teacher on EFL learners' writing and achievement. We can assume that having opportunity, pre-task instruction and task rehearsal can affect learners' writing and achievement in different settings and it is not context bound. It should also be noted that educational contexts, as well as schools' administrators provide high opportunity to promote pre-task instruction and task rehearsal so that EFL learners' writing will be improved.

The concept of task repetition may have explicit pedagogical implications. Task repetition research suggest insights into how instructors might develop and improve tasks during different phases of lessons. Research also shows the ways in which tasks might be related within lessons to provide learners with opportunities to work repeatedly with similar linguistic content. As a result, rather than focusing upon the performance of tasks in isolation (which characterizes much research to date), the task repetition notion shifts the focus of debate clearly towards the pedagogic use of tasks within lessons. 


\section{REFERENCES}

[1] Ahmadian, M. J., \& Tavakoli, M. (2011).The effects of simultaneous use of careful online planning and task repetition on accuracy, complexity, and fluency in EFL learners' oral production. Language Teaching Research, 15, 35-59.

[2] Allan, D. (1992). Oxford Placement Test. Oxford: Oxford University Press.

[3] Bauman, J., Bergeron, B. (1993). Story map instruction using children's literature: Effects on first graders' comprehension of central narrative elements. Journal of reading behavior, 25, 407-37.

[4] Brown, H. Salisch, S. (1996). Clustering: A model for the freshman thinking project. College Teaching, 4 (1), $29-33$.

[5] Bygate, M. (1996). Effects of task repetition: Appraising the developing language of learners. In J. Willis \& D. Willis (eds), Challenge and Change in Language Teaching. Oxford: Heinemann.

[6] Bygate, M.(2001). Effects of task repetition on the structure and control of oral language. In M. Bygate, P. Skehan and M. Swain (eds), Researching Pedagogic Tasks, Second Language Learning, Teaching and Testing. Harlow: Longman.

[7] Bygate, M. \& Samuda,V. (2005). Integrative planning through the use of task-repetition. In R. Ellis (Ed.), Planning and task performance in a second language (Vol. 11, pp. 37-74). Amsterdam: Benjamins.

[8] Carrell, P. L. (1989). Metacognitive Awareness and Second Language Reading. Modern Language Journal, 73, 121-133.

[9] Carroll, J.M. (2008). Geospatial Aspects of Activity Awareness. Technology, Design and Management: Creating New Models of Possibility for All, Monterrey, Mexico, April 3-5.

[10] Chenoweth, N. A., \& Hayes, J. R. (2001). Fluency in writing, generating text in L1 and L2.Written Communication, 18 (1), 8098.

[11] Cronin, J. J., \& Taylor, S. A.(1992). Measuring Service Quality: A Re-examination and Extension. Journal of Marketing, 56(3), $55-68$.

[12] Ellis, R. (1994). The study of second language acquisition. Oxford: Oxford University Press. 824pp.

[13] Ellis, R. (2003). Task-based language learning and teaching. Oxford: Oxford University Press.

[14] Ellis, R., \& Yuan, F. (2004). The effects of planning on fluency, complexity, and accuracy in second language narrative writing. Studies in Second Language Acquisition, 26: 59-84.

[15] Ellis, R. (2005). Planning and task performance in a second language. Philadelphia: John Benjamins.

[16] Ellis, R. (2008). The study of second language acquisition. Oxford: Oxford University Press.

[17] Ellis, R. \& Barkhuizen, G. (2005).Analyzing Learner Language. Oxford: Oxford University Press.

[18] Englert, C. S., \& Mariage, T. (1991). Shared understandings: Structuring the writing experience through dialogue. Journal of Learning Disabilities, 24, 330-342.

[19] Foster, P. \& Skehan, P. (1996). The influence of planning on performance in task-based learning. Studies in Second Language Acquisition. 18, 299-324.

[20] Foster, P. \& Skehan, P. (1999). The influence of source of planning and focus of planning on task-based performance. Language Teaching Research, 3(3), 215-247.

[21] Gass, S. Mackey, A., Alvarez-Torrez, M.J. \& Fernandez-Garcia, M. (1999). The effects of task repetition on linguistic output. [Electronic version]. Language Learning, 49,549-581.

[22] Heimlich, J.E. \& Pittelman, S.D. (1986). Semantic Mapping: Classroom Applications; International Reading Association. Newark: Delaware.

[23] Hunt, K. (1970). Syntactic maturity in school-children and adults. Monographs of the Society for Research in Child Development, 35. 229-233.

[24] Johnson, K. (1996). Language Teaching and Skill Learning. Oxford: Blackwel Publishing.

[25] Lantolf, J. (1996). Second language theory building: Letting all the flowers bloom! Language learning, 46: 713-746.

[26] Levelt, W. (1989). Speaking: From intention to articulation. Cambridge: MA: The MIT Press.

[27] Lipson, M. (1995). The effect of semantic mapping instruction on prose comprehension of below-level college readers. Reading Research and Instruction, 34, 367-378

[28] Lynch, T., \& Maclean, J. (2000). Exploring the benefits of task repetition and recycling for classroom language learning. Language Teaching Research. 4: 221-50.

[29] MacArthur, C. (1996). Student assistant for learning from text (SALT): A hypermedia reading aid. Journal of Learning Disabilities, 28, 150-159.

[30] Park, S. (1999). The influence of pre-task instructions and pre-task planning on focus on form during Korean EFL task-based interaction. Language Teaching Research, 14 (1), 9.

[31] Peresich, M.L. Meadows, J.D. Sinatra, R. (1990). Content Area Cognitive Mapping for Reading and Writing Proficiency. Journal of Reading. 33(6). 424-432.

[32] Reinders, H. (2009). Learner uptake and acquisition in three grammar-oriented production activities. Language Teaching Research, 13(2), 201-222.

[33] Robinson, P. (2001). Task complexity, task difficulty, and task production: Exploring Interactions in a componential framework. Applied Linguistics, 22:27-57.

[34] Roth, P. L. (1994). Missing data: A conceptual review for applied psychologists. Personnel Psychology, 47: 537-570.

[35] Skehan, P. (1996a). A framework for the implementation of task based instruction. Applied Linguistics, 17: 38-62.

[36] Skehan, P. (1998). A cognitive approach to language learning. Oxford: Oxford University Press.

[37] Skehan, P. (1998a).Task-based instruction. Annual Review of Applied Linguistics 18: 268-86.

[38] Skehan P. (1998b). A Cognitive Approach to Language Learning. Oxford: Oxford University Press.

[39] Skehan, P., \& Foster, P. (1999). The influence of task structure and processing conditions on narrative retellings. Language Learning, 49(1), 93-120.

[40] Skehan, P. \& Foster, P. (2001). Cognition and tasks in P. Robinson (Ed.), Cognition and second language instruction (pp.183205). Cambridge: Cambridge University Press. 
[41] Skehan, P. (2007). 'Re-examining Factors that Affect Task Difficulty in TBLA', ILI Language Teaching Journal, Vol.3 (1), 126.

[42] Tang, T. L. P. (1992). The effects of hardiness, police stress, and life stress on police officers' illness and absenteeism. Public Personnel Management, 21, 493-51.

[43] Zimmerman, R. (2000). L2 writing: Sub-processes, a model of formulating and empirical findings. Learning and Instruction, 10: 73-99.

Ghorbanali Salehi Aref received his B.A and M.A in English Language Teaching from Teachers University and Islamic Azad University Science and Research Branch of Tehran in 1999, 2013, respectively. He is an English teacher in secondary school. He has taught English for 25 years.

Ahmad Mojavezi received his M.A and Ph.D in English Language Teaching from Islamic Azad University of Najafabad Branch in 2009 and 2014, respectively. He is an assistant professor in Islamic Azad University of Zahedan. 